\title{
"Glass Ceiling" or "Sticky Floor": The Evidence from Chinese Labor Market
}

\author{
Yao Tang ${ }^{1, *}$, Rebecca Scott ${ }^{2}$ \\ ${ }^{1}$ School of Public Administration, Zhejiang University of Finance and Economics, China \\ ${ }^{2}$ School of Contemporary Chinese Studies, University of Nottingham, UK
}

Copyright $\bigcirc 2017$ by authors, all rights reserved. Authors agree that this article remains permanently open access under the terms of the Creative Commons Attribution License 4.0 International License

\begin{abstract}
Market-oriented economic reform brought great changes to the Chinese economy and society. The economic reforms accelerated after 1992, and a pattern of 'scientific development' and 'new normal' economics has developed since 2002. During this economic transitional process, issues of income distribution have kept attracting scholars' attention including: changes in earning distribution between genders; the effect of education, work experience, marriage and other factors on gender earnings and the differences among internal groups of women. This paper will use the data of the Chinese Household Income Projects in 2002 and 2013 to analyze earning disparity between genders and female inner groups. It finds that the 'glass ceiling effect' has intensified for women and the 'sticky floor effect' is still severe. Along with the earnings gap increasing between the genders, gender discrimination has also increased, and is particularly pronounced for women of higher earnings.
\end{abstract}

Keywords Unconditional Quintile Regression, Earnings Disparity, Gender Discrimination, Glass Ceiling Effect, Sticky Floor Effect

\section{Introduction}

Changes in earnings distribution have attracted the attention of researchers from all over the world. Some researchers focus on how market forces affect gender earnings inequality over time, such as Berik et al. [1], and Gustafsson et al. [2]. Several other studies examine gender earnings gaps in different areas, comparing the eastern seaboard provinces with western interior ones such as Liu et al. [3] and Ng [4]. Meanwhile, other researchers, such as Deng et al. [5] and Zhang et al. [6] have examined gender discrimination in various types of corporations, including state-owned enterprises and collective, private or joint venture enterprises.

The earlier literature that studies the gender wage gap consists of least squares regressions and Blinder-Oaxaca decomposition. As Autor et al. [7] has pointed out, these methods concentrate on the mean of the wage distribution and hence provide a limited understanding of the gender gap. More recent studies have examined gender earnings gaps across an earnings distribution and have not used a simple mean comparison, notably Barsky et al. [8], Chi et al. [9] [10], Ge et al. [11] and Li et al. [12]. This kind of analysis can provide more information which may be hidden in the mean-level analysis and can help to expose the real situation in regard to the earning gaps among different groups. For instance, Albrecht et al. [13] found there is an extremely large gap between men and women in Sweden in the top earnings group, but a mean-level analysis revealed the average gender gap in Sweden is quite small by international standards. Similarly, Bishop et al. [14] demonstrates that gender discrimination increased from 1988 to 1995 in China, but for higher income workers, it is actually decreased. Therefore extending the mean-level analysis to a distributional level analysis is essential if one wants to compare different parts of the earnings distribution.

This paper will implement recent advances in methodology and utilize the two-stage procedure proposed by Firpo et al. [15] [16] to analyze the situation of female workers in the labor market in urban China. The unconditional regression finds the negative effect on earnings of marriage and taking care of child has much decreased, especially for women. However, a higher return rate on education for female workers is not as significant as it was before and the rate of work experience has even fallen faster. Along with the gender earnings gap increasing, gender discrimination has also increased over time, and is particularly pronounced for women within the higher earnings group. This phenomenon can be partly regarded as the "glass ceiling" effect for women. The "sticky floor", the opposite scenario in which a plenty of women at the bottom of the wage distribution is greater is also verified in this paper.

The rest of this paper is organized as follows: Section 2 provides information about the data used in this paper and 
presents some basic facts on gender differences in the labor force. Section 3 illuminates the method of unconditional quantile regression and model specification. Section 4 outputs the empirical results and makes comparisons and section 5 sums up the whole paper and offers the main conclusions.

\section{Data Overview}

The data used in this paper is obtained from the Chinese Household Income Projects (CHIPs) in 2002 and 2013. Both surveys are supported by the Chinese Academy of Sciences (CAS), Asian Development Bank (ADB), Ford Foundation and East Asian Institute of Columbia University. They were designed to measure and estimate the distribution of personal income and related economic factors in China. The data was collected through a series of questionnaire-based interviews, and includes both urban and rural populations in China. The datasets contain 151 variables and 20632 cases for 2002, and 164 variables and 14683 cases for 2013 . The data covers aspects of the interviewees' personal characteristics and economic information, such as education and training, employment and social insurance situation, children's education and family and social relationships etc.

In order to better serve the research questions, the sample of this paper is restricted to the urban population, especially to women aged from 16 to 55 and men aged from 16 to 60 (the statutory retirement age is 55 for women and 60 for men in China in 2002 and 2013). Some sample input mistakes or obvious competing data have been corrected, for example one's schooling year which is significantly different from his or her education level. In addition, new variable 'earnings' is here defined as the sum of regular wages, floating wages, all kinds of bonuses, subsidies, cash income and allowances, and throughout the paper I focus on hourly earnings. Ultimately, this analysis of the data set produced 10,288 observations for 2002 and 6,709 observations for 2013 .

The main variables by gender are demonstrated in table 1 , from which it can be easily extrapolated that the male-female ratio of hourly earnings has increased three fold. The standard deviation for men is slightly larger than women in both years. The education gap decreased in 2002 and by almost the same amount in 2013. For other aspects, such as marital status, a comparison showed that less male and female workers got married. Changes in occupational proportions are also observable over time.

\section{Methodology}

\subsection{The Unconditional Quintile Regression Model}

After checking the descriptive statistics of the data, the earnings distribution and gender discrimination will be analyzed. The method used in this paper is based on the Recentered Influence Function (RIF) developed by Firpo et al. [15] [16] when they studied diffident effect of unionization at the lower and higher portion of wage distribution in the U.S. This method provides a computational regression model to evaluate the impact of changes in the distribution of explanatory variables (such as union status) on quintiles of the unconditional (marginal) distribution of a dependent variable (such as earnings). The advantage of the RIF method, as Zhu et al. [17] suggest, is that it can generate Oaxaca-Blinder decompositions for quintiles instead of the mean. Here it will decompose the earnings at different quantiles into the 'composition effect'-component attributable to the difference in productivity characteristics and the 'structure effect'-the unexplained component due to differences in the return from workers' characteristics, as Chi et al.[9] examined.

Table 1. Descriptive Statistics of Main Variables, 2002 and 2013

\begin{tabular}{|c|c|c|c|c|}
\hline Variable & Male/2002 & Female/2002 & Male/2013 & Female/2013 \\
\hline Demography (number of people) & 5699 & 4589 & 3964 & 2935 \\
\hline Work experience (years) & $\begin{array}{c}24.34 \\
\text { (sd. 10.62) }\end{array}$ & $\begin{array}{c}21.50 \\
\text { (sd. 9.86) }\end{array}$ & $\begin{array}{c}21.15 \\
\text { (sd. 11.82) }\end{array}$ & $\begin{array}{c}18.10 \\
\text { (sd. 10.80) }\end{array}$ \\
\hline Year of schooling & $\begin{array}{c}11.47 \\
\text { (sd. 3.07) }\end{array}$ & $\begin{array}{c}11.34 \\
\text { (sd. 2.91) }\end{array}$ & $\begin{array}{c}12.19 \\
\text { (sd. 2.99) }\end{array}$ & $\begin{array}{c}19 \\
\text { (sd. 3.02) }\end{array}$ \\
\hline Married (\%) & 49.23 & 38.72 & 48.89 & 35.64 \\
\hline Have a child under six (\%) & 14.2 & 14.82 & 13.32 & 13.86 \\
\hline Owner of private firm (\%) & 0.57 & 0.29 & 9.21 & 4.43 \\
\hline Self-employed (\%) & 4.33 & 4.2 & 0.59 & 0.25 \\
\hline Professional (\%) & 20.15 & 22.54 & 24.54 & 21.39 \\
\hline Administrative staff and manager (\%) & 15.04 & 4.83 & 21.85 & 26.60 \\
\hline Total earnings per hour (RMB) & $\begin{array}{c}6.13 \\
\text { (sd. 5.47) }\end{array}$ & $\begin{array}{c}5.18 \\
\text { (sd. 4.99) }\end{array}$ & $\begin{array}{c}20.41 \\
\text { (sd. } 23.64)\end{array}$ \\
\hline
\end{tabular}

Source: Chinese Household Income Project, 2002 and 2013.

Note: A few of occupation categories were deleted for the convenience of comparisons between different years. 
The decomposition procedure consists of two steps: the first step resembles Dinardo et al. [18] and decomposes the overall changes in the earnings distribution to a change in differences in characteristics and a change in returns to these characteristics. A counter factual earnings distribution is constructed showing what earnings women would get if they received the same returns to their work characteristics as men. If the $\mathrm{v}(\mathrm{Y})$ represents a quantile of the earnings distribution of $\mathrm{Y}$, The overall differences can be decomposed as in equation (1):

$$
\mathrm{v}\left(\mathrm{Y}_{\mathrm{m}}\right)-\mathrm{v}\left(\mathrm{Y}_{\mathrm{f}}\right)=\left[\mathrm{v}\left(\mathrm{Y}_{\mathrm{m}}\right)-\mathrm{v}\left(\mathrm{Y}_{\mathrm{c}}\right)\right]+\left[\mathrm{v}\left(\mathrm{Y}_{\mathrm{c}}\right)-\mathrm{v}\left(\mathrm{Y}_{\mathrm{f}}\right)\right]
$$

in this equations, $Y_{m}$ and $Y_{f}$ represent earnings of male workers and female workers respectively, $Y_{c}$ is a counter factual earnings expression which can be obtained by reweighting observations of the female, as Firpo et al.[16] suggested. The counter factual earnings demonstrates what women would earn if they receive the same returns to their characteristics as men. Thus, the earnings gap between men and women can be written as a sum of the "composition effect" $v\left(Y_{m}\right)-v\left(Y_{c}\right)$, plus the "structure effect" $v\left(Y_{c}\right)-$ $\mathrm{v}\left(\mathrm{Y}_{\mathrm{f}}\right)$. The reweighting factor is defined as:

$$
\varphi_{\mathrm{i}}=\frac{\left[1-\mathrm{p}\left(\mathrm{X}_{\mathrm{i}}\right)\right] \mathrm{p}}{\mathrm{p}\left(\mathrm{X}_{\mathrm{i}}\right)(1-\mathrm{p})}
$$

Here $p(X)$ is "the probability of a worker being a male given individual attributes $X$ " and $p$ denotes the proportion of males in the population. In practice, $p(X)$, which can be regarded as the propensity score, is derived from a logit/probit regression. Therefore the reweighted data, product of male earnings distribution and the possibility of male workers and his propensity, can be thought of as realization of the counter factual earnings distribution. This first step of decomposition is semi-parametric because it does not assume any functional form for the earnings distribution and only employs a logit or probit specification in estimating the reweighing factor.

The second step is to further decompose the "composition effect" and "structure effect" into the contribution of each individual covariate. In this procedure, the Recentered Influence Function (RIF) is used to represent the influence of an individual observation on the quantile of earnings. Its function can be written as $\mathrm{E}\left[\operatorname{RIF}\left(\mathrm{Y} ; \mathrm{q}_{\tau}\right) \mid \mathrm{X}\right.$. By taking iterated expectations, the marginal effects of covariates on the quantile of earnings are estimated. The RIF assumes a linear specification as the OLS regression:

$$
\left.\left.\mathrm{E}\left[\mathrm{RIF}\left(\mathrm{Y} ; \mathrm{q}_{\tau}\right) \mid \mathrm{X}\right]=\mathrm{X} \beta\right)\right]
$$

Here the coefficient $\boldsymbol{\beta}$ represents the marginal effects of the explanatory variables $X$ at the earnings quantile $\mathrm{q}_{\tau}$. For both years, 2002 and 2013, the RIF estimates the contribution of explanatory variables for male and female at quantiles of earnings, as well as the counter factual earning structure for females:

$$
\widehat{\operatorname{RIF}}\left(\mathrm{Y}_{\mathrm{k}} ; \hat{\mathrm{q}}_{\tau}\right)=\mathrm{X}_{\mathrm{k}} \widehat{\beta}_{\mathrm{k}}, \mathrm{k}=\mathrm{m}, \mathrm{f}, \mathrm{c}
$$

Here the subscripts $\mathrm{m}, \mathrm{f}, \mathrm{c}$, represent the male, female, and counter factual earning structure for women, respectively, $\widehat{\operatorname{RIF}}\left(\mathrm{Y}_{\mathrm{k}} ; \widehat{\mathrm{q}}_{\tau}\right)$ denotes the RIF estimate for the $\boldsymbol{\tau}^{\text {th }}$ quantile and the $\hat{\beta}$ represents the estimate of the quantile partial effect. Using the RIF regression from equation 4, the decomposition of gender earnings gap at different quantiles can be given as follows:

$$
\begin{array}{r}
\hat{\mathrm{q}}_{\tau}\left(\mathrm{Y}_{\mathrm{m}}\right)-\widehat{\mathrm{q}}_{\tau}\left(\mathrm{Y}_{\mathrm{f}}\right)=\left[\left(\overline{\mathrm{X}}_{\mathrm{m}} \hat{\beta}_{\mathrm{m}}-\overline{\mathrm{X}}_{\mathrm{f}} \widehat{\beta}_{\mathrm{c}}\right)+\widehat{\mathrm{R}}_{\tau}^{\mathrm{c}}\right]+\left[\overline { \mathrm { X } } _ { \mathrm { f } } \left(\widehat{\beta}_{\mathrm{c}}-\right.\right. \\
\left.\left.\widehat{\beta}_{\mathrm{f}}\right)+\widehat{\mathrm{R}}_{\tau}^{\mathrm{s}}\right](5)
\end{array}
$$

$\hat{\mathrm{q}}_{\tau}\left(\mathrm{Y}_{\mathrm{m}}\right)-\hat{\mathrm{q}}_{\tau}\left(\mathrm{Y}_{\mathrm{f}}\right)$ represents the gender earnings difference at the $\boldsymbol{\tau}^{\text {th }}$ quantile. $\bar{X}$ represents the vector of covariate averages. $\hat{\beta}_{c}$ is from the counterfactual distribution which assumes the male returns to personal characteristics for women. Thus, $\bar{X}_{m} \hat{\beta}_{m}-\bar{X}_{f} \hat{\beta}_{c}$ represents the "composition effect," which is caused by the pension disparities between genders. $\bar{X}_{f}\left(\widehat{\beta}_{c}-\widehat{\beta}_{f}\right)$ represents the "structure effect" which is caused by gender discrimination and $\widehat{R}_{\tau}^{c}$ and $\widehat{R}_{\tau}^{s}$ are the errors of these effects.

\subsection{Model Specification}

The model specification will be used log earnings per hour for males and females respectively as a function of the following variables:

I. Years of schooling;

II. Work experience which is age-years of schooling;

III. Marriage, 1 for married, 0 for other else;

IV. Whether have a young child under 6 years old, 1 for have, 0 for not;

V. Indicator variable for occupation (white collar for default variable);

VI. Ownership (S.O.E for default variable)

VII. Industry (Manufacture for default variable)

VIII. Regions (eastern region, central region, and western region);

Variables from i) to iv) are the ones with which this paper most concerned. Educational level and work experience are commonly thought to be positively related to workers' earnings. Work experience here is deemed to be a continuous variable, which is the square of years of working, because it is thought that work experience grows following time worked. The effect of marital status on income is different for women and men. Padavic et al. [19] states that married men will have higher earnings than single and married women as they generally have a sense of bread-earning responsibility for their family, thus they have more motivation to put more effort and energy into their work leading to resulting higher pay.

In contrast, marital status has negative effect on women's earnings for the same reason. The majority of female workers are indeed spending more time on family life, especially after they have had a child. In addition, working mothers face discrimination because of the perception above that family responsibility make them less productive. As Zhang et al. [20] verified the perceived expense of maternity benefits is another factor leading to lower pay for female 
workers. Therefore a child, especially young child, is thought to have downside effect on women earnings, whereas for men, it seems have little effect. In China, children generally go to school at 6 years old, and before that, mother generally spent more time to take care of them.

Different type of occupation not only mean different kinds of human capital, which to some extent determines the income level, but also implies occupational barriers among various types of jobs. Therefore, the effect of different occupations, ownerships and industries will be controlled. The types of occupation are summarized as private enterprise owner, white collar, blue collar and others. For ownership of corporation five forms are classified: state owned enterprise (S.O.E), collectives, private enterprises, foreign-owned or joint venture and others. As for the types of industry, manufacture is the default variable and the others are construction, transportation, commerce, real estate, education, sciences and research, government, social welfare, financial sectors and other industries.

\section{Empirical Results}

\subsection{Preliminary Description of Gender Earning Distribution}

Table 2 estimates the earnings distribution for male and female at different quantiles. The mean gender earnings gap increases from 1.18 (2002) to 1.31 (2013), and changes a lot at various quantiles. In 2002, the male-female ratio of earnings is larger in lower paid groups. The situation reversed in 2013 in that the prominent earnings gap fell over the last decile, the higher earnings group. This upside-down ratio variation implies that the earnings of upper income group of women do not increase following the same pattern as the other groups. The "glass ceiling effect" for women has become worse in China.

The enlarged gap within the inner male groups demonstrates a similar trend to the one which Goos et al. [21] characterized as a pattern of "polarization of the labour market.' Employment polarizes into high-wage and low-wage jobs at the expense of the middle-wage jobs. In
China post the economic transition, this trend seems to be more complicated in that male workers within the upper income group are the biggest winners, not only at the cost of middle-income of men, but also at the cost of women.

\subsection{RIF Unconditional Quantile Regression Result}

\subsubsection{Earnings Gap Decompositions}

In this section, the decompositions of the male-female earnings gap are performed by RIF unconditional regression. The outcomes are shown in table 3. It gives the 'earning gap', 'unexplained gap' and 'unexplained ratio' at different quantiles (P5, P10, P25, P50, P75, P90 and P95) in 2002 and 2013. The 'unexplained ratio' represents the ratio value of the unexplained part of the earnings differential to the total earnings gap. At the same time, the results from the traditional OLS regression are also calculated to achieve a contrast in results with the differing methodological approaches.

The findings from the OLS suggest the mean earnings gap increased from 2002 to 2013. The unexplained earnings gap had the same rising tendency, which demonstrates the fact that the whole situation of the earning environment has deteriorated for female workers. This finding is according to results from Demurger et al. [22] which shows that the economic transition brought about some significant discriminatory behaviors and affected differently the segments of the urban labour market. After examining the various quantiles of earnings, a much more detailed conclusion about each group can be drawn.

In 2002, the biggest gender earning gap emerges at P10 and the smallest is at P75, supporting the "sticky floor" hypothesis in China. The unexplained gender earnings gap is highest at P95 and lowest at P75. The lower earning group bears the largest earning gap, but the least gender discrimination. Conversely the higher group endures the largest unexplained gap, but less of an earning gap. In 2013, the largest earnings gap reaches its peak at P90 and touches its base at P5. Furthermore, the paid environment for women has worsened wholly. The ratio of gender discrimination enlarges at every quantile comparison given. 
Table 2. Unconditional Quantile Earnings Distribution Comparison, 2002 and 2013

\begin{tabular}{|c|c|c|c|c|c|c|}
\hline & \multicolumn{3}{|c|}{2002} & \multicolumn{3}{|c|}{2013} \\
\hline & Male & Female & M/F Ratio & Male & Female & M/F Ratio \\
\hline Mean & $\begin{array}{c}6.13 \\
\text { (sd. } 5.471)\end{array}$ & $\begin{array}{c}5.18 \\
\text { (sd. } 4.985 \text { ) } \\
\end{array}$ & 1.18 & $\begin{array}{c}16.37 \\
\text { (sd. } 23.639) \\
\end{array}$ & $\begin{array}{c}12.54 \\
\text { (sd. 18.080) }\end{array}$ & 1.31 \\
\hline P10 & 1.94 & 1.46 & 1.32 & 4.69 & 3.75 & 1.25 \\
\hline P50 & 5.09 & 4.09 & 1.24 & 12.5 & 9.38 & 1.33 \\
\hline P90 & 10.92 & 9.47 & 1.15 & 31.25 & 23.13 & 1.35 \\
\hline P90 : P10 & 5.63 & 6.49 & 1 & 6.66 & 6.17 & 1 \\
\hline P50 : P10 & 2.62 & 2.80 & I & 2.67 & 2.5 & I \\
\hline P90 : P50 & 2.15 & 2.32 & 1 & 2.5 & 2.47 & I \\
\hline
\end{tabular}

Source: Chinese Household Income Project, 2002 and 2013.

Note: Earnings are at 2002 and 2013 price respectively.

Table 3. RIF Earning Gaps and Decomposition, 2002 and 2013

\begin{tabular}{|c|c|c|c|c|c|c|c|c|}
\hline & P5 & P10 & P25 & P50 & P75 & P90 & P95 & OLS \\
\hline 2002 Earning Gap & .2634 & .3041 & .2899 & .2391 & .1499 & .1802 & .2166 & .2458 \\
\hline 2002 Unexplained Gap & .1582 & .2132 & .1975 & .1605 & .0875 & .1273 & .1687 & .1683 \\
\hline 2002 Unexplained Ratio & .6006 & .7011 & .6813 & .6713 & .5837 & .7064 & .7789 & .6851 \\
\hline 2013 Earning Gap & .1696 & .2531 & .3087 & .3231 & .2562 & .3377 & .2560 & .3056 \\
\hline 2013 Unexplained Gap & .1504 & .2181 & .2757 & .2900 & .2158 & .3033 & .2459 & .2732 \\
\hline 2013 Unexplained Ratio & .8868 & .8617 & .8931 & .8976 & .8423 & .8981 & .9605 & .8941 \\
\hline
\end{tabular}

Source: Chinese Household Income Project, 2002 and 2013.

\subsubsection{Earnings Return to Personal Characteristics}

This section examines the effect of personal characteristics (years of schooling, work experience, marital status and a young child in family) on earnings at the different quantiles using RIF unconditional regression. The results are shown in table 4. Meanwhile, outcomes from the OLS are also demonstrated to make a contrast.

The effect of education has been repeatedly discussed in the research on earning distribution, such as Byron et al.[23] and $\mathrm{Wu}$ et al.[24]. Zhang et al. [25] using the data of the 1995 and 2002 from the same project estimated an increased coefficient between education and earnings. In this research, the results from the OLS report follow the same trend, as shown in table 4 . It is easy to get an impression that the education effect on man earnings has kept almost the same, while its effect on females had dropped. Although the female return rate on education is higher than that of males as a whole, it decreases when one's earnings go up. In addition, male workers get more earnings than their female counterparts from additional education. As demonstrated below for the P75 in 2013, it appears to be an increasing tendency on return rate from schooling in the lower half earnings. For the higher earnings group (quintile 75 to 95 ) for both sexes, the effect of education declines and the drop is more significant for women. This finding is a bit ironic in the context of the Chinese structural transformation of the economy, which relies on knowledge-based industries. 
Table 4. Earnings Return Comparison between Different Groups and Genders, 2002 and 2013

\begin{tabular}{|c|c|c|c|c|c|c|c|c|c|c|c|c|c|c|c|c|}
\hline \multirow{2}{*}{2002} & \multicolumn{2}{|c|}{ P5 } & \multicolumn{2}{|c|}{ P10 } & \multicolumn{2}{|c|}{ P25 } & \multicolumn{2}{|c|}{ P50 } & \multicolumn{2}{|c|}{ P75 } & \multicolumn{2}{|c|}{$\mathrm{P} 90$} & \multicolumn{2}{|c|}{ P95 } & \multicolumn{2}{|c|}{ OLS } \\
\hline & M & F & M & $\mathrm{F}$ & M & F & M & $\mathrm{F}$ & M & $\mathrm{F}$ & M & F & M & $\mathrm{F}$ & M & F \\
\hline Education & $\begin{array}{c}0.042^{* *} \\
*\end{array}$ & $0.063 * * *$ & $0.054 * * *$ & $0.066 * * *$ & $0.048 * * *$ & $0.065^{* * *}$ & $0.047 * * *$ & $0.057 * * *$ & $0.044 * * *$ & $0.049 * * *$ & $0.041^{* * *}$ & $0.044 * * *$ & $0.046^{* * *}$ & $0.036 * * *$ & $0.046^{* * *}$ & $0.054 * * *$ \\
\hline Experience & $\begin{array}{c}0.030^{* *} \\
* \\
\end{array}$ & 0.025 & $0.051 * * *$ & $0.041^{* *}$ & $0.083 * * *$ & $0.053 * * *$ & $0.095 * * *$ & $0.057 * * *$ & $0.109 * * *$ & $0.067 * * *$ & $0.101 * * *$ & $0.066^{* * *}$ & $0.113 * * *$ & $0.079 * * *$ & $0.066^{* * *}$ & $0.058 * * *$ \\
\hline Marriage & 0.076 & 0.103 & 0.122 & 0.073 & 0.015 & -0.016 & 0.034 & 0.018 & $0.039^{*}$ & 0.02 & $0.010^{*}$ & -0.006 & $0.018^{*}$ & 0.028 & $0.064 *$ & 0.035 \\
\hline Child & 0.077 & -0.068 & 0.017 & -0.05 & 0.051 & 0.006 & 0.036 & 0.024 & 0.044 & 0.03 & $0.041^{*}$ & 0.063 & 0.010 & 0.011 & $0.052^{*}$ & -0.011 \\
\hline $\begin{array}{l}\text { Eastern } \\
\text { Region }\end{array}$ & $\begin{array}{c}0.386^{* *} \\
* \\
\end{array}$ & $0.255^{* * *}$ & $0.306 * * *$ & $0.211 * * *$ & $0.289 * * *$ & $0.239 * * *$ & $0.291 * * *$ & $0.298 * * *$ & $0.315 * * *$ & $0.329 * * *$ & $0.383 * * *$ & $0.391 * * *$ & $0.514 * * *$ & $0.421 * * *$ & $0.362 * * *$ & $0.302 * * *$ \\
\hline $\begin{array}{c}\text { Midland } \\
\text { Region }\end{array}$ & 0.069 & $\begin{array}{c}-0.159^{* *} \\
*\end{array}$ & $-0.059 *$ & $\begin{array}{c}-0.221 * * \\
*\end{array}$ & $\begin{array}{c}-0.108 * * \\
*\end{array}$ & $\begin{array}{c}-0.229 * * \\
*\end{array}$ & $\begin{array}{c}-0.095^{* *} \\
*\end{array}$ & $\begin{array}{c}-0.204 * * \\
*\end{array}$ & $\begin{array}{c}-0.081 * * \\
*\end{array}$ & $\begin{array}{c}-0.152 * * \\
*\end{array}$ & $-0.071 * *$ & $\begin{array}{c}-0.125^{* *} \\
*\end{array}$ & -0.042 & $-0.081 * *$ & $-0.050^{*}$ & $\begin{array}{c}-0.152^{* *} \\
*\end{array}$ \\
\hline Adjusted $\mathbf{R}^{2}$ & 0.153 & 0.219 & 0.242 & 0.274 & 0.241 & 0.293 & 0.242 & 0.227 & 0.245 & 0.207 & 0.194 & 0.168 & 0.125 & 0.129 & 0.328 & 0.353 \\
\hline \multirow{2}{*}{2013} & \multicolumn{2}{|c|}{ P5 } & \multicolumn{2}{|c|}{ P10 } & \multicolumn{2}{|c|}{$\mathrm{P} 25$} & \multicolumn{2}{|c|}{ P50 } & \multicolumn{2}{|c|}{ P75 } & \multicolumn{2}{|c|}{$\mathrm{P} 90$} & \multicolumn{2}{|c|}{ P95 } & \multicolumn{2}{|c|}{ OLS } \\
\hline & M & $\mathrm{F}$ & M & $\mathrm{F}$ & $\mathrm{M}$ & $\mathrm{F}$ & $\mathrm{M}$ & $\mathrm{F}$ & $\mathrm{M}$ & $\mathrm{F}$ & $\mathrm{M}$ & $\mathrm{F}$ & $\mathrm{M}$ & $\mathrm{F}$ & M & $\mathrm{F}$ \\
\hline Education & $\begin{array}{c}0.052^{* *} \\
*\end{array}$ & $0.067 * * *$ & $0.059 * * *$ & $0.072 * * *$ & $0.061 * * *$ & $0.058^{* * *}$ & $0.061 * * *$ & $0.049 * * *$ & $0.061 * * *$ & $0.046 * * *$ & $0.059 * * *$ & $0.042 * * *$ & $0.057 * * *$ & $0.052 * * *$ & $0.055^{* * *}$ & $0.058^{* * *}$ \\
\hline Experience & 0.01 & -0.015 & $0.038^{*}$ & 0.01 & $0.048 * * *$ & 0.01 & $0.050^{* * *}$ & 0.019 & $0.049 * * *$ & 0.018 & $0.051 * * *$ & $0.031^{*}$ & $0.053 * *$ & $0.048^{* *}$ & $0.038 * * *$ & $0.017 *$ \\
\hline Marriage & 0.087 & 0.096 & $0.169^{* *}$ & $0.110^{*}$ & $0.127^{*}$ & $0.104 * *$ & $0.119 * *$ & 0.083 & $0.101 *$ & $0.090^{*}$ & $0.115^{*}$ & $0.109^{*}$ & $0.121^{*}$ & 0.098 & $0.118^{* *}$ & $0.079 * *$ \\
\hline Child & 0.049 & -0.028 & 0.063 & -0.016 & $0.091 *$ & -0.002 & $0.080^{*}$ & $0.023^{*}$ & 0.07 & $0.025^{*}$ & 0.083 & $0.051^{*}$ & 0.074 & 0.045 & $0.070^{*}$ & $-0.023^{*}$ \\
\hline $\begin{array}{l}\text { Eastern } \\
\text { Region }\end{array}$ & $\begin{array}{c}0.433^{* *} \\
*\end{array}$ & $0.405 * * *$ & $0.507 * * *$ & $0.412 * * *$ & $0.515 * * *$ & $0.398 * * *$ & $0.518 * * *$ & $0.377 * * *$ & $0.499 * * *$ & $0.367 * * *$ & $0.550 * * *$ & $0.331 * * *$ & $0.604 * * *$ & $0.305 * * *$ & $0.493 * * *$ & $0.396^{* * *}$ \\
\hline $\begin{array}{c}\text { Midland } \\
\text { Region }\end{array}$ & -0.072 & $-0.117 * *$ & 0.035 & -0.02 & 0.056 & 0.017 & 0.01 & 0.063 & 0.019 & 0.036 & 0.006 & 0.066 & 0.013 & 0.059 & 0.013 & 0.002 \\
\hline Adjusted $\mathbf{R}^{2}$ & 0.144 & 0.211 & 0.214 & 0.240 & 0.250 & 0.241 & 0.246 & 0.240 & 0.223 & 0.230 & 0.186 & 0.162 & 0.119 & 0.116 & 0.339 & 0.327 \\
\hline
\end{tabular}

Source: Chinese Household Income Project, 2002 and 2013.

Notes: 1 . Child means the effect of having a little child in family; $\mathrm{M}$ for male and $\mathrm{F}$ for female;

2. ${ }^{*} \mathrm{p}<0.05 ;{ }^{* *} \mathrm{p}<0.01 ; * * * \mathrm{p}<0.001$;

3. Eastern region and midland region is compared with the western region which is set as dummy variable. 
The return to work experience declines for both male and female with their earnings increasing in 2002. Woman's experience was more rewarding than men's in 2002. These findings are broadly consistent with the findings of others who have looked at earnings inequality such as Appleton et al. [26], Meng et al. [27] and Zhang et al. [28]. While in 2013, the overall return to work experience declines, especially for females. This drop is so significant that it reverses the fact that in 2002 female work experience is more rewarding and positive. In 2013, the return rates are even minus for the upper half earnings group of women and it can thus be concluded that females gain less with their ages grow.

Economic development and market formulation may gradually shift attitudes about woman's role in household work and childrearing as Zhu et al. [17] suggested. These shifts include a more egalitarian attitude towards gender roles in the family. Married women transfer some attention from family to work to grasp the career promotion opportunities for higher pay. The impact of marriage on the earnings distribution for male and females is demonstrated in this paper and is in accordance with this statement. In 2002 , the return of marital status is positive for men, but for women, it is negative. While in 2013, females had almost the same rate with males at least in middle-earnings group.

Another factor that does the greatest damage to the earnings of a married woman is having babies. A Chinese mother, whose career interrupted by giving birth ('second child policy' has been in place since 2015) has to spend much time taking care of the child, especially the little ones. Therefore the impact of having a child younger than 6 years old is estimated. Results from unconditional quantile research suggest that in 2002, women and men suffered differently from having a young child. This was especially the case for women of higher earnings. The more they earned, the greater they sacrificed. In contrast, in 2013, there was no significant difference between men and women. Male workers don't have any advantage when compared with females when having a small child. On the contrary, both of the effects for female and males are negative without a distinct difference.

In short, the gender comparisons provided by the RIF unconditional quantile regression demonstrates significant changes have taken place since 2002. Education, although still essential to women, is not as rewarding as it was in 2002. Similarly, the promotion effect of work experience declines largely and turns out to be negative for women of higher earnings. Married status is no longer a help for men in gaining more from the labor market. The gender differential in the effect of having a little child is not as significant as before, and presents a negative impact for both.

\section{Conclusions}

In order to offer comprehensive understandings of the women earnings situation in China, the two-step procedure of RIF unconditional regression was adopted to examine gender discrimination and returns to personal characteristics at various quantiles. The advantage of this methodology is that it can decompose the unconditional earnings change at any quantile of the earning distribution. In addition, it also allows an estimate of the contribution of individual covariates to each component. In this research, four personal characteristics (years of schooling, work experience, marital status and having young child in family) were estimated.

After analyzing the samples from CHIP 2002 and 2013 by RIF, the results show that both the overall gender earnings gap and gender discrimination has increased since 2002. The earnings gap is more significant for the higher earnings group. The 'glass ceiling effect' is very obvious in China and has become worse. In addition, it also featured a large change in terms of contributions for different individual variables to earnings. Education, although it is still essential for females, is not as much rewarding as in 2002. The same trend happened to work experience. As for marital status, it does not help men to acquire more earnings from labor market. In terms of the effect of having little child in family, the differential returns between genders is not as significant as before, and presents a wholly negative effect for both. All these comparisons between genders and changes demonstrate the substantial changes within the Chinese economy and society.

\section{Acknowledgements}

We thank Social Science Funds of Ministry of Education (China) for grant support (Reference Number: 17yjc840034).

\section{REFERENCES}

[1] Berik, G., Rodgers, Y. and Zveglich, J. E. (2004), 'International Trade and Gender Wage Discrimination: Evidence from East Asia', in Review of Development Economics, 8(2): 237-254.

[2] Gustafsson, B. and Li, S. (2000), 'Economic transformation and the gender earnings gap in urban China' in Journal of Population Economics, 13(2): 305-329.

[3] Liu, P., Meng, X. and Zhang, J. (2000), 'Sectoral gender wage differentials and discrimination in the transitional Chinese economy', in Journal of Population Economics, 13(2): 331-352.

[4] Ng, Y. (2007), 'Gender Earnings Differentials and Regional Economic Development in Urban China, 1988-97', in Review of Income and Wealth, 53(1): 148-166.

[5] Deng, Q. and Li, S. (2009), 'What Lies behind Rising Earnings Inequality in Urban China? Regression-based 
Decompositions', in CESifo Economic Studies, 55(3-4): 598-623.

[6] Zhang, L. and Dong, X. (2008), 'Male-female wage discrimination in Chinese industry Investigation using firm-level data', in Economics of Transition, 16(1): 85-112.

[7] Autor, D. H., Katz, L. F. and Kearney, M. S. (2006), 'The Polarization of the U.S. Labor Market', in American Economic Review, 96: 189-194.

[8] Barsky, R., Bound, J., Charles, K. K. and Lupton, J. P. (2002), 'Accounting for the Black-White Wealth Gap: A Nonparametric Approach', in Journal of the American Statistical Association, 97(459): 663-673.

[9] Chi, W. and Li, B. (2008), 'Glass ceiling or sticky floor? Examining the gender earnings differential across the earnings distribution in urban China, 1987-2004', in Journal of Comparative Economics, 36(2): 243-263.

[10] Chi, W., Li, B. and Yu, Q. (2011), 'Decomposition of the increase in earnings inequality in urban China: A distributional approach', in China Economic Review, 22(3): 299-312.

[11] Ge, Y., Li, H. and Zhang, J. (2011), 'Gender earnings gaps in Hong Kong: Empirical evidence from across the earnings distribution in 2006', in China Economic Review, 22(1): 151-164.

[12] Li, L. and Dong, X. (2011), 'Economic Transition and the Gender Earnings Gap in Chinese Industry: The Role of Firm Characteristics', in Contemporary Economic Policy, 29(1): 67-87.

[13] [13] Albrecht, J., Björklund, A. and Vroman, S. (2003), 'Is There a Glass Ceiling in Sweden?', in Journal of Labor Economics, 21(1):145-177.

[14] Bishop, J. A., Luo, F. and Wang, F. (2005), 'Economic Transition, Gender Bias, and the Distribution of Earnings in China', in Economic of Transition, 13(2): 239-259.

[1] Firpo, S., Fortin, N. M. and Lemieux, T. (2007), 'Decomposing wage distributions using recentered influence function regressions', Unpublished Manuscript, University of British Columbia, Available at:

http://www.economie.uqam.ca/pages/docs/lemieux_thomas.p df

[15] Firpo, S., Fortin, N. M. and Lemieux, T. (2009), 'Unconditional quantile regressions', in Econometrica, 77: 953-973.
[16] Zhu, P. and Zhang, Z. (2012), 'Unconditional Quantile Regression: Literature Review and Empirical Example' in Statistical Research, 29(3): 88-96.

[17] DiNardo, J., Fortin, N. M. and Lemieux, T. (1996), 'Labor Market Institutions and the Distribution of Wages, 1973-1992: A Semiparametric Approach', in Econometrica, 64(5): 1001-1044.

[18] Padavic, I. and Reskin, B. F. (2002), Women and men at work, Thousand Oaks: Pine Forge Press.

[19] Zhang, Y., Hannum, E. and Wang, M. (2008), 'Gender-based Employment and Income Differences in Urban China: Considering the Contributions of Marriage and Parenthood', in Social Forces, 86(4): 1529-1560.

[20] Goos, M. and Manning, A. (2003), 'Lousy and Lovely Jobs: The Rising Polarization of Work in Britain', discussion paper: No DP0604, London School of Economics, Available at: http://www.mitpressjournals.org/doi/pdfplus/10.1162/rest.89. 1.118

[21] Démurger, S., Fournier, M. and Chen, Y. (2007), 'The evolution of gender earnings gaps and discrimination in urban China, 1988-95', in The Developing Economies, 45(1): 97-121.[23]

[22] Byron, R. P. and Manaloto, E. Q. (1990), 'Returns to education in China', in Economic Development and Cultural Change, 38:783-796.

[23] Wu, X. and Xie, Y. (2003), 'Does the market pay off? Earnings returns to education in urban China', in American Sociological Review, 68(3): 425-442.

[24] Zhang, J., Zhao, Y., Park, A. and Song, X. (2005), 'Economic returns to schooling in urban China, 1988 to 2001', in Journal of Comparative Economics, 33(4): 730-752.

[25] Appleton, S., Song, L. and Xia, Q. (2013), 'Understanding urban wage inequality in China 1988-2008: Evidence from quantile analysis', IZA Discussion Paper No. 7101, Available at

http://papers.ssm.com/sol3/papers.cfm?abstract_id=2199784 \#\#

[26] Meng, X. and Miller, P. (1995), 'Occupational Segregation and Its Impact on Gender Wage Discrimination in China Rural Industrial Sector', in Oxford Economic Papers-New Series, 47(1): 136-155.

[27] Zhang, J., Han, J., Liu, P. and Zhao, Y. (2008), 'Trends in the Gender Earnings Differential in Urban China, 1988-2004', in Industrial and Labor Relations Review, 61(2): 224-243. 